\title{
Computed tomography-guided localization of small lung nodules before video-assisted resection: Experience with an efficient hook-wire system
}

\author{
S. Wicky, MD, ${ }^{a}$ M. Dusmet, MD, ${ }^{b}$ F. Doenz, MD, ${ }^{a}$ H. B. Ris, MD, ${ }^{b}$ P. Schnyder, MD, and F. Portier, MD, \\ Lausanne, Switzerland
}

$\mathrm{T}$ he rate of successful video-assisted thoracoscopic surgery (VATS) for resection of pulmonary nodules has improved since the development of radiologic localization techniques. The failure rate has decreased from $45 \%$ to $5 \%$. $^{1}$ Several techniques have been described, including methylene blue injection, hook-wire localization, and combined techniques, but none has proved entirely satisfactory. ${ }^{2-5}$ We report our experience with a mammographic hook-wire system with characteristics that appear to offer an efficient anchorage.

\section{Patients and Methods}

Between September 1999 and December 2001, a total of 20 patients underwent localization of pulmonary nodules (mean size $7.8 \mathrm{~mm}$, range 4-25 $\mathrm{mm}$ ) before VATS resection. The mean distance from skin to lesion was $70 \mathrm{~mm}$ (range $50-100 \mathrm{~mm}$ ), and the mean distance from pleura to nodule was $14 \mathrm{~mm}$ (range 5-30 mm). A mammographic hook-wire system (Ariadne's Thread; Biosphere Medical, Louvres, France), consisting of an 8-mm diameter circular hook-wire connected to a 50-cm long suture thread was used.

A 20-gauge, 10-cm long needle contains the hook, which regains its circular coniguration after being delivered from the

From the Departments of Radiology ${ }^{\mathrm{a}}$ and General Surgery, ${ }^{\mathrm{b}}$ University Hospital, Lausanne, Switzerland.

Received for publication Dec 11, 2001; accepted for publication Feb 5, 2002.

Address for reprints: Michael Dusmet, MD, Consultant Thoracic Surgeon, The Royal Brompton Hospital, Sydney St, London SW3 6NP, United Kingdom (E-mail: M.Dusmet@rbh.nthames.nhs.uk).

J Thorac Cardiovasc Surg 2002;124:401-3

Copyright (C) 2002 by The American Association for Thoracic Surgery

$0022-5223 / 2002 \$ 35.00+0 \quad \mathbf{1 2 / 5 4 / 1 2 4 2 5 7}$

doi: $10.1067 / \mathrm{mtc} .2002 .124257$ system. Figure 1 depicts the computed tomography-guided procedure, which is performed with the patient under local anesthesia through as direct a route as possible, without crossing a fissure. The hook-wire is then delivered around the nodule, anchoring the system into the lung, and the needle is withdrawn (Figure 2). The patient is then taken to the operating room. At the beginning of the VATS procedure, the nylon thread is pulled into the chest to reduce the risk of migration of the hook during manipulation of the lung. The nodule is then palpated. When this is not possible, palpation of the lung in the area of the nodule will cause the hook-wire to move, allowing its localization. The lung is then grasped, and a standard wedge resection is performed. The specimen is then removed in a bag and sent to the pathologist for immediate frozen-section examination.

\section{Results}

All nodules were localized, and the VATS resections were all successful, despite more or less extensive adhesions between the lung and the chest wall in 3 cases. All resections were complete, and no conversions to thoracotomy were required.

The mean computed tomography-guided procedure time was 14 minutes (range 10-22 minutes). Three minimal pneumothoraces $(<5 \mathrm{~mm})$ required no treatment. One pneumothorax, which required drainage, occurred in a patient whose VATS procedure was delayed for 24 hours. No migration of the circular hook was observed (mean time to surgery 2 hours and 50 minutes).

Macroscopic examination of the surgical specimens showed that all hooks were located in or around the nodule. Fourteen nodules were benign and 6 were malignant (primary lung cancer, $\mathrm{n}=4$; metastatic cancer, $\mathrm{n}=2$; granuloma, $\mathrm{n}=5$; fibrous scar, $\mathrm{n}=5$, hamartoma, $\mathrm{n}=3$, and pulmonary infarct, $\mathrm{n}=1$ ). 

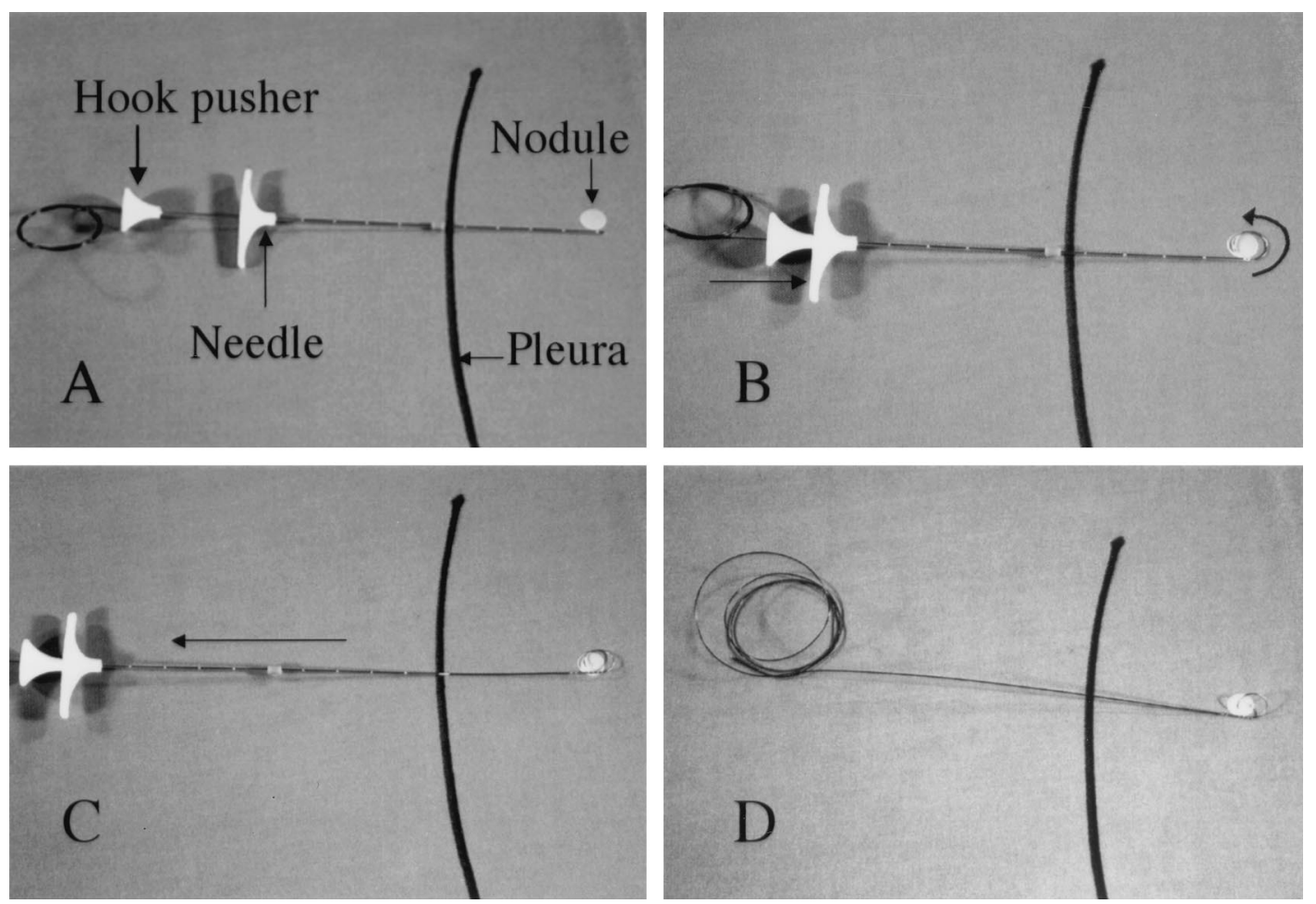

Figure 1. Black line simulates pleural surface, and white dot represents pulmonary nodule. A, Tip of needle is advanced just beside nodule, so that circular rigid hook will curl around it. Tip of needle is turned so that hook will encircle nodule. B, Hook pusher is advanced, and circular hook goes around nodule. C and D, Needle and hook pusher are removed, leaving hook-wire system in place.
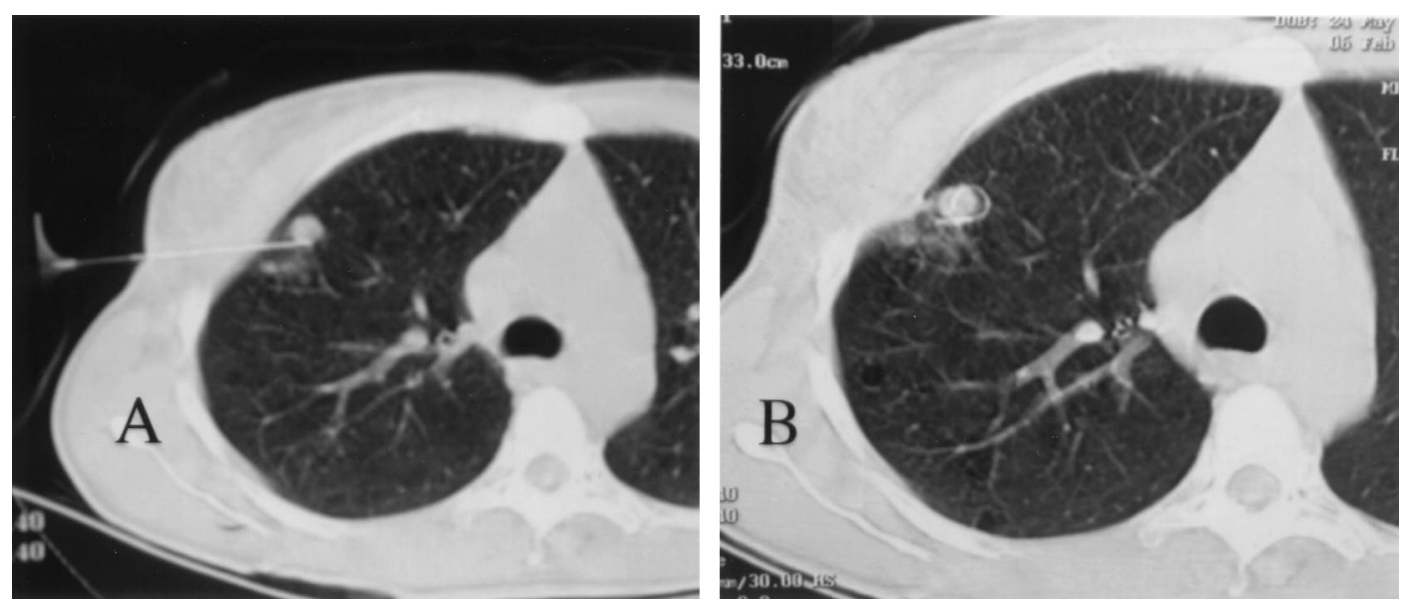

Figure 2. A, Computed tomographic section (5-mm slice thickness) with needle tip located beside nodule. B, Computed tomographic section (5-mm slice thickness) after localization and withdrawal of needle and hook pusher. Circular hook is visible around and inside nodule 


\section{Discussion}

The technique of methylene blue localization was used in our institution $^{2}$ with some satisfaction. Difficulties were encountered during the VATS procedure when pleural diffusion of the methylene blue was observed or when the nodule was not subpleural in location. Hook-wire pulmonary nodule localization is another technique. Rigid hook-wires must be proscribed, as respiratory movements may cause migration. Other hook-wire systems also presented high rates of dislocation, occurring mostly during the VATS procedure. Homemade hook-wire systems have also been described. ${ }^{3,4}$

We report the use of a novel hook-wire system for the localization of lung nodules. The system that we used was developed for the localization of breast nodules. Our experience has shown it to be simple to use this system for lung nodule localization. Its anchorage in the lung parenchyma was efficient, allowing all nodules to be identified and resected even in the 3 cases in which adhesions between the lung and the chest wall required extensive manipulation of the lung during surgery. This system has allowed nodules as deep as 30 $\mathrm{mm}$ below the pleura to be located and resected.

All patients were referred for the diagnosis of a lung nodule that was considered to be potentially malignant. Thus all underwent the diagnostic procedure as soon as feasible. All patients with a primary lung cancer underwent a formal anatomic resection with mediastinal lymph node dissection. No further resections were performed in all other cases.

The morbidity associated with the procedure consisted entirely of minor pneumothoraces. It was similar to that seen in our experience with methylene blue localization. ${ }^{2}$

Our experience with 20 cases of pulmonary nodule localization with the Ariadne's Thread hook-wire system proved completely satisfactory to both the radiologist and the surgeon. We strongly recommend this system's use.

\section{References}

1. Suzuki K, Nagai K, Yoshida J, Ohmatsu H, Takahashi K, Nishimura M, et al. Video-assisted thoracoscopic surgery for small indeterminate pulmonary nodules: indications for preoperative marking. Chest. 1999;115:563-8.

2. Vandoni RE, Cuttat JF, Wicky S, Suter M. CT-guided methylene-blue labelling before thoracoscopic resection of pulmonary nodules. Eur J Cardiothorac Surg. 1998;14:265-70.

3. Mullan BF, Stanford W, Barnhart W, Galvin JR. Lung nodules: improved wire for CT guided localization. Radiology. 1999;211:561-5.

4. Kanazawa S, Ando A, Yasui K, Mitani M, Hiraki Y, Shimizu N, et al. Localization of pulmonary nodules for thoracoscopic resection: experience with a system using a short hookwire and suture. AJR Am J Roentgenol. 1998;170:332-4.

5. De Kerviler E, Gossot D, Frija J. Localization techniques for the thoracoscopic resection of pulmonary nodules. Int Surg. 1996;81:241-4. 